\title{
Effects of Adjuvant Low-Dye Kinesio Taping, Adjuvant Sham Taping, or Extracorporeal Shockwave Therapy Alone in Plantar Fasciitis: A Randomized Double-Blind Controlled Trial
}

\author{
Yeliz Bahar-Ozdemir ${ }^{1}$ and TUĞBA ATAN² \\ ${ }^{1}$ Sultan Abdulhamid Han Egitim ve Arastirma Hastanesi \\ ${ }^{2}$ SBÜ Gaziler Fizik Tedavi ve Rehabilitasyon Eğitim ve Araştırma Hastanesi
}

November 29, 2020

\begin{abstract}
Aim Extracorporeal shockwave therapy (ESWT) is known as one of the most effective treatment methods in plantar fasciitis $(\mathrm{PF})$. Low-dye taping, which is the most preferred method of banding treatments, provides an analgesic effect by correcting biomechanics. It was aimed to compare the efficacy of adjuvant low-dye kinesio-taping (KT), sham-taping, or extracorporeal shockwave therapy (ESWT) alone in plantar fasciitis (PF). Methods In this double-blind, sham-controlled study, forty-five patients with PF were randomized to 3-group (Group 1: ESWT plus low-dye KT, $\mathrm{n}=15$; Group 2: ESWT plus Sham-taping, $\mathrm{n}=15$; and Group 3: ESWT only, $\mathrm{n}=15$ ) five-session ESWT were administrated. KT was performed and changed every 1-week for the ESWT sessions in Groups 1 and 2. The main outcome measures were the visual analog scale (VAS) change, the heel tenderness index (HTI), foot function index (FFI). The patients were evaluated at the beginning and end of the treatment and the 4-week follow-up. Results The demographic characteristics and baseline outcomes between groups were similar ( $\mathrm{p}>0.05$ ). VAS and HTI changes were observed in all three groups, there was no difference between groups. Repeated-measures ANOVA showed a significant interaction between the time and the groups in FFI-total (F3.919=2.607; p=.043). At the 4-week follow-up, when Groups 1 and 2 were evaluated, the lower FFI-total, FFI-disability, and FFI-activity limitation were statistically significant in Group 1 ( $\mathrm{p}=0.027 ; \mathrm{p}=0.026 ; \mathrm{p}=0.029$, respectively). When Group 1 and 3 were compared, the decrease in FFI-pain and FFI-activity limitation were significant in Group $1(\mathrm{p}=0.042 ; \mathrm{p}=0.035$, respectively). Conclusions Low-dye KT, in addition to ESWT, is more effective than sham-taping and ESWT in pain relief and foot function improvement due to PF at a 4-week follow-up.
\end{abstract}

\section{Hosted file}

Plantar fasciitis main manuscript-IJCP.pdf available at https://authorea.com/users/379754/ articles/495948-effects-of-adjuvant-low-dye-kinesio-taping-adjuvant-sham-taping-orextracorporeal-shockwave-therapy-alone-in-plantar-fasciitis-a-randomized-double-blindcontrolled-trial

\section{Hosted file}

Table 1.pdf available at https://authorea.com/users/379754/articles/495948-effects-ofadjuvant-low-dye-kinesio-taping-adjuvant-sham-taping-or-extracorporeal-shockwavetherapy-alone-in-plantar-fasciitis-a-randomized-double-blind-controlled-trial

\section{Hosted file}

Table 2-kalkaneal revizyon.pdf available at https://authorea.com/users/379754/ articles/495948-effects-of-adjuvant-low-dye-kinesio-taping-adjuvant-sham-taping-or- 
extracorporeal-shockwave-therapy-alone-in-plantar-fasciitis-a-randomized-double-blindcontrolled-trial

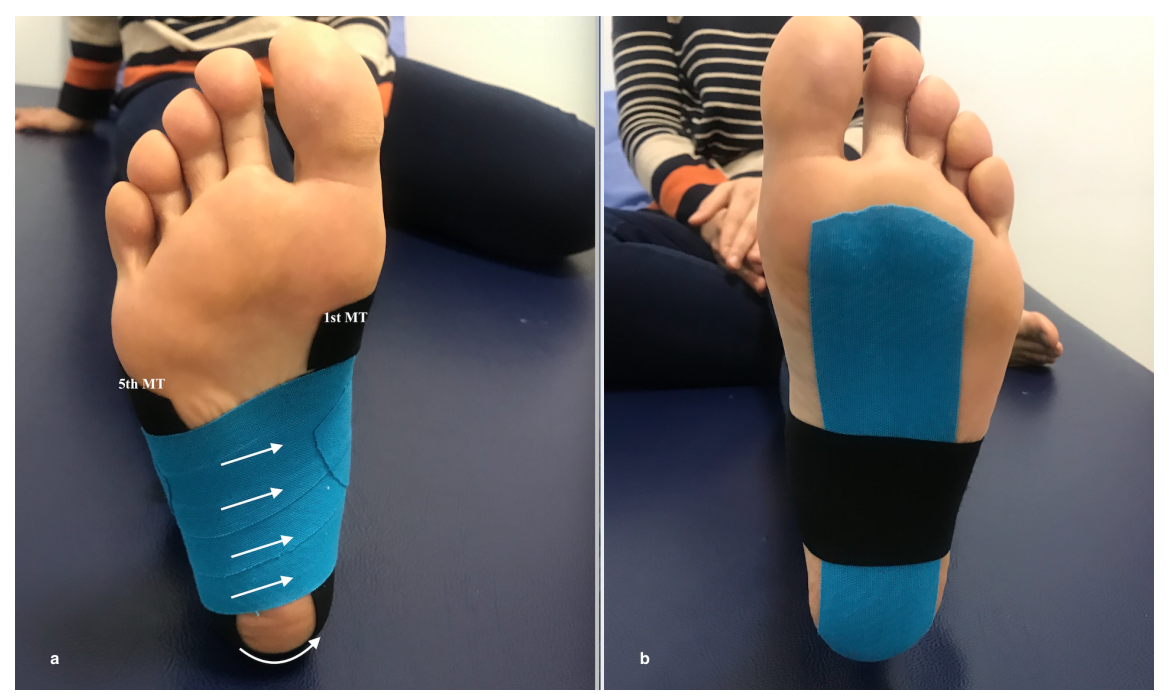




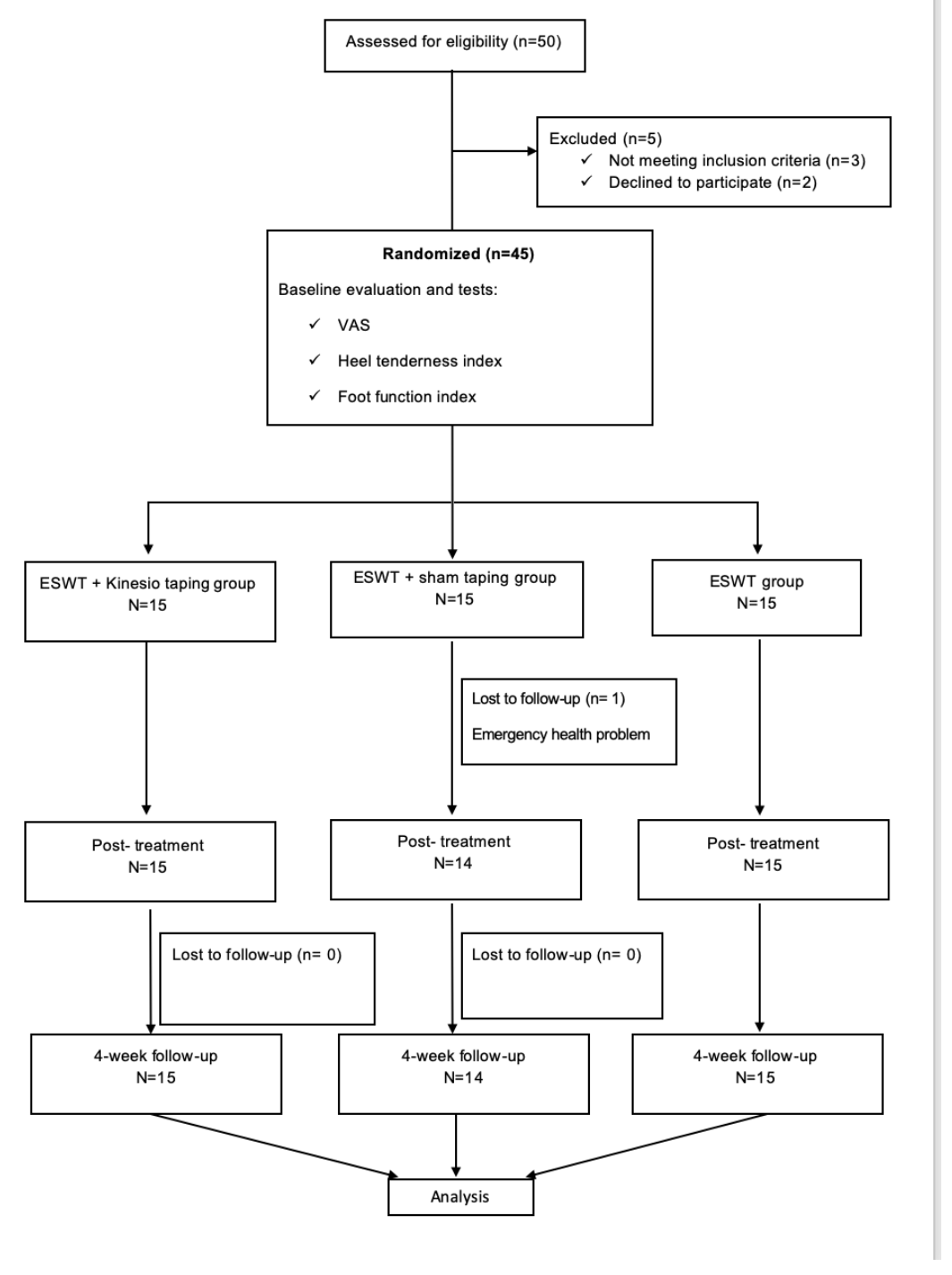



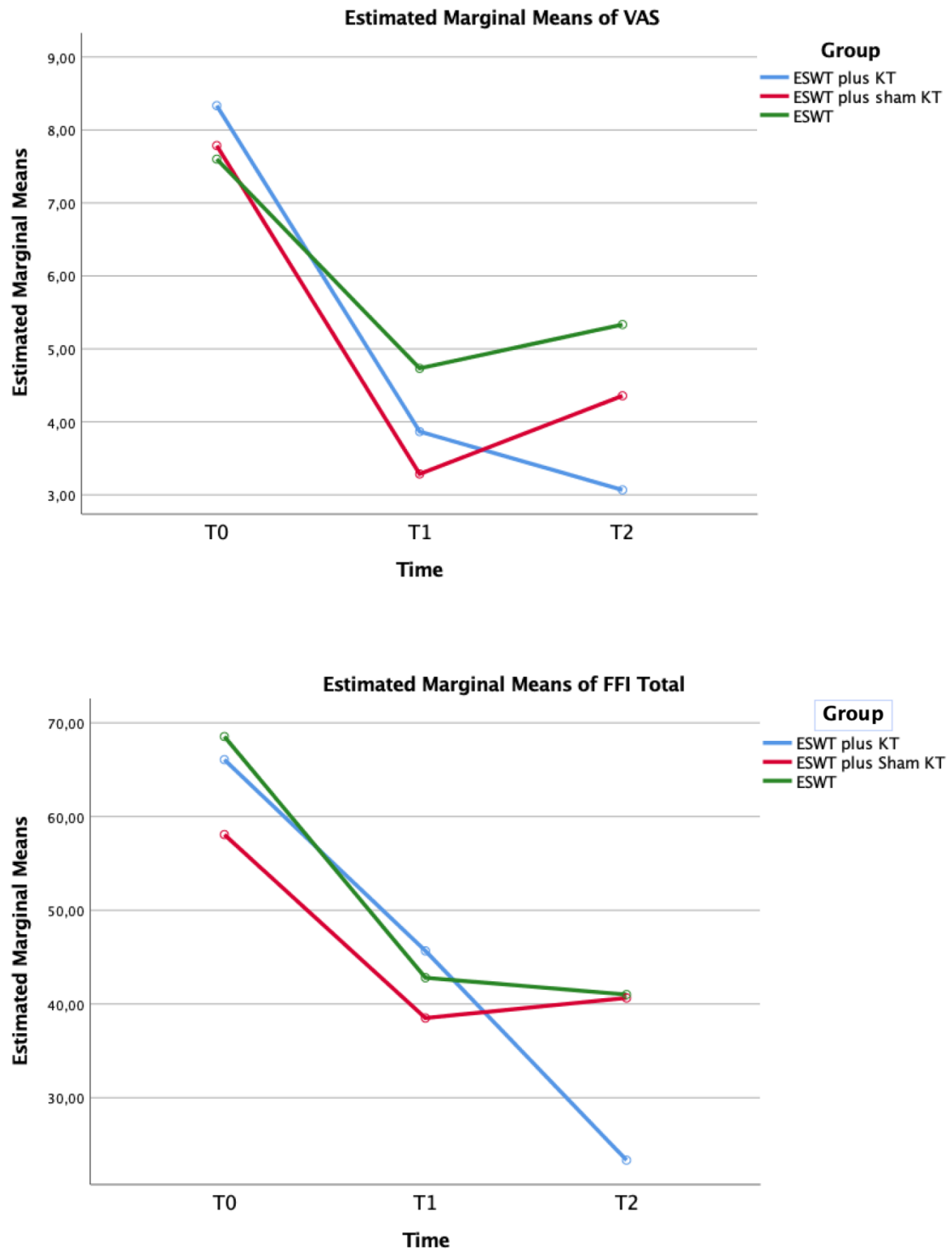

4 